\title{
Modelling of single spark interactions during electrical discharge coating
}

\author{
Samer J Algodi, ${ }^{a, d}$ Adam T Clare ${ }^{* a, b}$, Paul D Browna, \\ aDepartment of Mechanical, Materials and Manufacturing Engineering; ' Institute of Advanced \\ Manufacturing, Faculty of Engineering; ${ }^{\mathrm{C}}$ Nanoscale and Microscale Research Centre, University of \\ Nottingham, University Park, Nottingham, NG7 2RD, UK; ${ }^{\mathrm{d}}$ Department of Mechanical Engineering, \\ College of Engineering, Al-Nahrain University, Baghdad, Iraq \\ Corresponding author: adam.clare@ nottingham.ac.uk
}

\begin{abstract}
Electrical discharge coating (EDC) methods may be used to enhance the surface functionality of electrical discharge machined components. However, industrial uptake of EDC has been restricted due to limited understanding of the fundamental interactions between energy source and workpiece material. The fraction of energy transferred to the workpiece, $F_{v}$, as a consequence of sparking, is an important parameter which affects directly crater geometry and the microstructural development of the near surface modified layer. In this paper, a 2D transient heat transfer model is presented using finite difference methods, validated against experimental observations, to estimate effective values for $F_{v}$ as a function of processing conditions. Through this method we can predict coating layer thicknesses and microstructures through appropriate consideration of heat flow into the system. Estimates for crater depths compared well with experimentally determined values for coating layer thicknesses, which increased with the increasing fraction of energy transfer to the workpiece. Predictions for heat transfer and cooling of melt pools, arising from single spark events, compared well with experimental observations for the developed cermet microstructures. In particular, intermediate processing conditions were associated with the development of complex, banded, fine-grained microstructures, reflecting differences in localised cooling rates and the competing pathways for heat conduction into the substrate and convection within the dielectric fluid. Increased pulse-on times were associated with a propensity towards increasing grain size and columnar growth, reflecting the higher energies imparted into the coatings and slower cooling rates.
\end{abstract}

Key words: Electrical discharge coating; finite difference method; single spark modelling; microstructure 


\section{Nomenclature}

\begin{tabular}{|c|c|c|c|}
\hline \multicolumn{2}{|r|}{ Symbols } & $R_{p}$ & Empirical constant \\
\hline $\mathrm{a}$ & Constant & $R_{p c}$ & Plasma channel radius $(\mu \mathrm{m})$ \\
\hline$c_{p}$ & Specific heat capacity (J/kg.K) & $r$ & Radial distance $(\mathrm{m})$ \\
\hline ED & Electric discharge & $T$ & Temperature $(\mathrm{K})$ \\
\hline EDC & Electrical discharge coating & $T_{m}$ & Melting temperature $(\mathrm{K})$ \\
\hline EDM & Electric discharge machining & $T_{s}$ & Initial temperature $(\mathrm{K})$ \\
\hline FEM & Finite element method & $T_{\infty}$ & Dielectric fluid temperature $(\mathrm{K})$ \\
\hline$F_{v}$ & $\begin{array}{l}\text { Fraction of energy transferred to the } \\
\text { workpiece }\end{array}$ & $t$ & Time (s) \\
\hline HSFC & High speed framing camera & $t_{\text {on }}$ & Pulse-on time $(\mu \mathrm{s})$ \\
\hline$h$ & $\begin{array}{l}\text { Convection heat transfer coefficient } \\
\qquad\left(\mathrm{W} / \mathrm{m}^{2} . \mathrm{K}\right)\end{array}$ & $u_{\infty}$ & Velocity of the fluid $\left(\mathrm{m}^{2} / \mathrm{s}\right)$ \\
\hline$I$ & Current (A) & $\mathrm{V}$ & Voltage $(\mathrm{V})$ \\
\hline$k$ & Thermal conductivity (W/m.K) & $x \& y$ & Cartesian coordinates \\
\hline$L$ & Workpiece length $(\mathrm{m})$ & $2 \mathrm{D}$ & Two dimensions \\
\hline$L_{m}$ & Latent heat of melting $(\mathrm{J} / \mathrm{kg})$ & & \\
\hline MMC & Metal matrix composite & & $\begin{array}{c}\text { Greek letters } \\
\end{array}$ \\
\hline$m$ & Constant & $\alpha$ & Thermal diffusivity $\left(\mathrm{m}^{2} / \mathrm{s}\right)$ \\
\hline$N u_{x}$ & Nusselt number (-) & $\alpha$ & Modified thermal diffusivity $\left(\mathrm{m}^{2} / \mathrm{s}\right)$ \\
\hline$n$ & Constant & $\mu$ & Dynamic viscosity of the fluid (kg/m.s) \\
\hline $\operatorname{Pr}$ & Prandtl number (-) & $\rho$ & Density $\left(\mathrm{kg} / \mathrm{m}^{3}\right)$ \\
\hline$q$ & Convection heat flux $\left(\mathrm{W} / \mathrm{m}^{2}\right)$ & & \\
\hline$q_{0}$ & Maximum heat flux $\left(\mathrm{W} / \mathrm{m}^{2}\right)$ & & Subscripts \\
\hline$R e$ & Reynolds number (-) & $\mathrm{i} \& \mathrm{j}$ & Iteration in $\mathrm{x} \& \mathrm{y}$ direction \\
\hline
\end{tabular}

\section{Introduction}

Electrical discharge coating (EDC) is an adaptation of electrical discharge machining (EDM), which is able to deposit high melting point materials, such as hard-wearing, electrically conductive ceramics, onto a substrate, using a semi-sintered tool electrode. EDM is considered as a non-contact process that can be used to machine challenging electrically conductive materials, regardless of their mechanical properties of hardness, toughness or strength (Lin et al., 2008). Even though the first reported use of EDM was recorded in the late 1940s (Singh et al., 2004), it is still considered to be a non-conventional machining process when compared to more conventional, shear-based machining methods. The EDM process involves transient phenomena, between solid, liquid and gas/plasma phases, with chemical reactions leading to mass transfer and boundary displacement (Kunieda et al., 2005), necessitating a consideration of the electrodynamics, thermodynamics and hydrodynamics of the system (Yeo et al., 2008). During ED processing, material is removed by a series of discrete electrical discharges between two electrodes immersed in a medium of dielectric fluid, through conversion of electrical energy into thermal energy (Singh and Bhardwaj, 2011). The energy distribution into the workpiece material may be estimated with reference to the physical properties of the electrodes in question, by assuming either all the electrical energy is converted into heat (Singh and 
Shukla, 2012); or by using refined process models, using either analytical (Yeo et al., 2007) or numerical approaches (Das et al., 2003) based on underpinning electro-thermal and electromechanical mechanisms of material removal (Tan and Yeo, 2008). However, there is variability in the bases of these modelling approaches, for single spark events, which consider a variety of heat sources (e.g. point, cylindrical or Gaussian) and assume different levels of energy transfer, in order to calculate temperature distributions, crater geometries and the volume of material removed.

A comprehensive comparison by Yeo et al. (Yeo et al., 2008) of five different EDM electrothermal models, in terms of temperature distribution, material removal and crater geometry, demonstrated that the model of Di Bitonto et al. (DiBitonto et al., 1989), which assumed only $18 \%$ of energy was transferred to the cathode, showed better agreement with experimental data than other models which assumed $50 \%$ energy transfer, leading to an overestimate of workpiece temperature and resulting crater size. Indeed, the assumption of a constant fraction of energy transferred to the workpiece is considered one of the main reasons for variability between modelling and experimental data (Singh, 2012).

With regard to the various attempts to estimate the energy distribution between anode, cathode and dielectric fluid during EDM, Okada et al. (Okada et al., 2000) modelled energy distribution correlated against a simple thermocouple measurement of both workpiece and electrode temperature. Conversely, Singh (Singh, 2012) considered the fraction of energy transferred to the cathode, for different discharge parameters, utilising heat transfer principles, to show that the fraction of energy increased from $6.1 \%$ to $26.8 \%$ with increasing current and pulse-on time (total energy per discharge event). Further, Xia et al. (Xia et al., 1996) determined the energy distribution to anode and cathode by measuring and calculating electrode temperature as a function of position. In this case, a finite difference method was utilised iteratively, with assumed energy loss converging on $\sim 40 \%$ and $\sim 25 \%$ to the anode and cathode, respectively, when the temperatures coincided. The alternative approach of Zhang et al. (Zhang et al., 2014) to determine plasma diameter and energy distribution during EDM compared experimentally determined boundaries of molten material (i.e. crater morphology) with an finite element method (FEM) thermo-physical model, and showed that expansion of the plasma diameter should be taken into consideration, under conditions of fixed current, for consistency.

Hence, from literature, it is evident that the proportion of energy transferred into the workpiece during electric discharge is a critically important factor in defining model fidelity. Further, there has been no modelling to date of spark/material interactions during the related 
process of electric discharge coating (EDC). In this paper, a 2D transient heat transfer model is developed, using finite difference methods, drawing on the approaches of Xia et al. (Xia et al., 1996) and Zhang et al. (Zhang et al., 2014), to estimate the effective heat transfer into a workpiece during EDC. Interpolation, based on current and pulse-on time, allowed the plasma radius and Gaussian heat flux distribution into the workpiece to be predicted. Further, the model allows for fundamental interactions between energy source and workpiece during EDC processing to be explored, with consideration of original coating / workpiece material properties enabling the prediction of coating layer thicknesses and the microstructural rearrangements, upon the associated rapid cooling phase.

\section{Process modelling and simulation}

A simple and comprehensive model is now presented to help explain single spark interactions during ED processing. Energy is imparted into the workpiece from the plasma channel, with material on the scale of the plasma channel diameter experiencing a rapid heating and cooling phase, during pulse-on and pulse-off times, respectively.

\subsection{Heating phase}

\subsubsection{Governing equations and boundary conditions}

A two dimensional axisymmetric transient heat transfer model was developed, to facilitate improved understanding of electro-thermal heating for a single discharge incident upon a workpiece surface. The finite difference domain was defined with dimension $3 \times 1.5$ times the crater radius, in both the $x$ and $y$ directions, respectively; with a uniform square mesh of grid spacing $\Delta x=\Delta y=0.5 \mu \mathrm{m}$. Figure 1 illustrates the Gaussian heat distribution and interaction with the workpiece along with the associated boundary conditions used for the analysis. The initial temperature $T_{s}$ of the workpiece is taken as the ambient temperature; the material properties of the electrodes and dielectric are considered temperature-independent; and the time increment is set at $\Delta t=10^{-8} \mathrm{~s}$. 


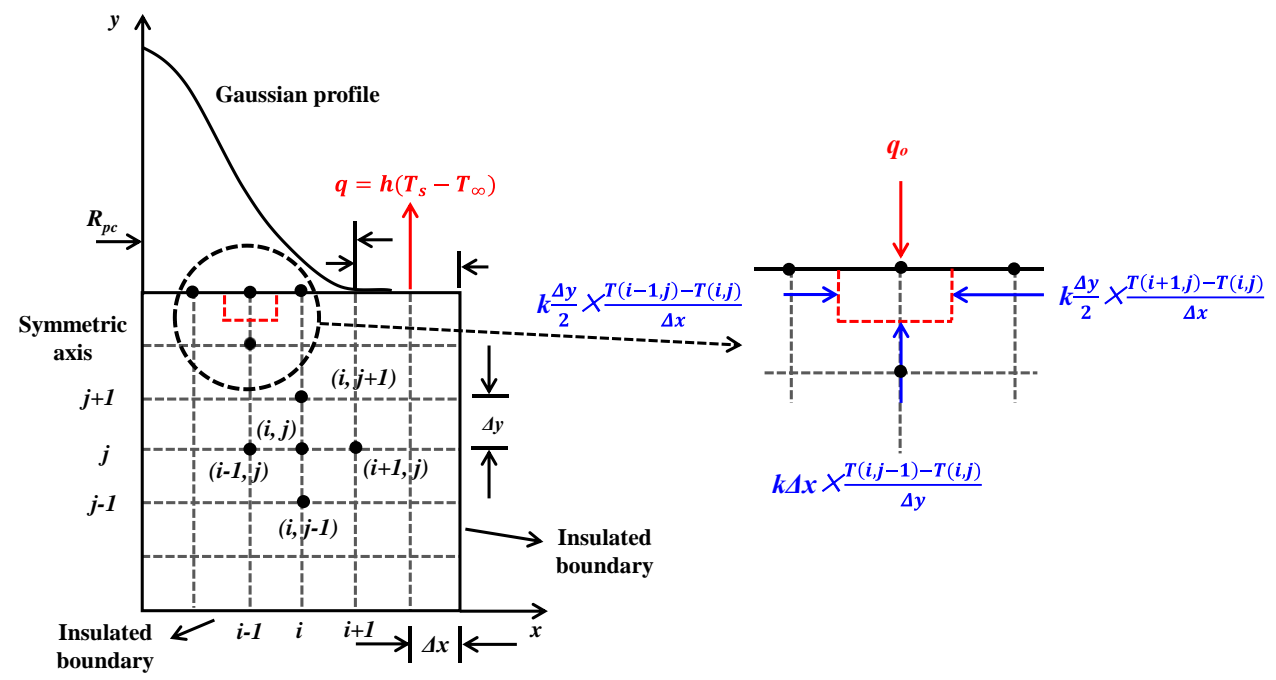

Figure 1 Gaussian profile heat source and boundary conditions with the workpiece, including interior node and expanded view of top surface boundary node.

Conduction without heat generation is considered the main mode of heat transfer between a plasma channel and workpiece, for example as shown by (Kansal et al., 2008) as well as (Joshi and Pande, 2010) although some heat loss from the top surface of the workpiece is anticipated due to convective flow of the dielectric fluid, which is considered in more detail during the 'Cooling phase' (Section 2.2). For simplification, radiative heat losses are neglected here.

The governing Fourier heat conduction equation, taking into account the boundary conditions, is given by:

$$
\partial^{2} T / \partial x^{2}+\partial^{2} T / \partial y^{2}=1 / \alpha \partial T / \partial t
$$

Where $T$ represents the temperature, and $x$ and $y$ are Cartesian coordinates, used to represent radial distance from the centre of the crater, and distance below the specimen surface, respectively; $t$ represents time (i.e. pulse-on time); and $\alpha$ represents thermal diffusivity $\left(\mathrm{m}^{2} / \mathrm{s}\right)$, expressed as:

$$
\alpha=k / \rho c_{p}
$$

Where $k$ is thermal conductivity $(\mathrm{W} / \mathrm{m} . \mathrm{K}) ; \rho$ is density $\left(\mathrm{kg} / \mathrm{m}^{3}\right)$; and $c_{p}$ is the specific heat capacity (J/kg.K). When the temperature of the workpiece reaches a specified level during processing, some of the crater material melts and evaporates, whilst some of the tool electrode material becomes deposited on the workpiece surface which then re-solidifies. Latent heat is exchanged as a result of this phase transition and hence the term for thermal diffusivity $\alpha^{\prime}$ requires modification and is used as in (Zhang et al., 2014):

$$
\alpha^{\prime}=k / \rho\left(c_{p}+L_{m} / T_{m}\right)
$$


Where $L_{m}$ represents the latent heat of fusion $(\mathrm{J} / \mathrm{Kg})$ and $T_{m}$ is the melt temperature $(\mathrm{K})$.

\subsubsection{Heat flux and energy distribution}

The effective energy transferred into the workpiece is characteristic of the amount of energy available and the shape of the heat distribution profile. It is widely accepted that the plasma heat source during EDM processing approximates a Gaussian distribution, for example as has been approximated by (Das et al., 2003) and (Zhang et al., 2013) amongst others. The Gaussian distribution of heat flux is given by:

$$
q(r)=q_{0} \exp \left(-n\left(r / R_{p c}\right)^{2}\right)
$$

With maximum heat flux $q_{0}\left(\mathrm{~W} / \mathrm{m}^{2}\right)$ given by:

$$
q_{0}=4.57 F_{v} \mathrm{VI} / \pi R_{p c}^{2}
$$

Where $r$ is radial distance from the centre of a single spark; $R_{p c}$ is the plasma channel radius; $F_{v}$ is the fraction of total energy transferred to the workpiece; and $\mathrm{V}$ and $I$ are voltage and current, respectively. The exponent $n$ used in equation (4) serves to define the Gaussian distribution. The heat flux profile becomes steep when $n<-4.5$ and becomes flat with any increase of $n$ to a value approaching zero (Izquierdo et al., 2009). Further, Shen et al. (Shen et al., 2014) report that the energy distribution characteristic was affected by the shape of the electrode, with enhanced energy distributed into the workpiece from a needle-shaped electrode. For the present work, based on the use of a flat electrode, a value of $n=-3$ was selected based on previous studies, for example from (Somashekhar et al., 2015), also in agreement with work of (Tao et al., 2012).

It is recognised that there are inherent difficulties in measuring the plasma channel radius $R_{p c}$, due to the small distance between the two electrodes ( 10 - $100 \mu \mathrm{m}$ (Kunieda et al., 2005)) where the plasma occurs at very short pulse-on times (few microseconds). Schulze et al. (Schulze et al., 2004) used a high speed framing camera (HSFC) to analysis the discharge process, but experienced difficulties analysing the light emission due to the effects of debris and bubbles which serve to obscure the spark gap. Descoeudres et al. (Descoeudres et al., 2005) used spatially-resolved optical emission spectroscopy to investigate the plasma created during 
EDM and reported very fast development of the plasma, with formation $<50 \mathrm{~ns}$ after dielectric breakdown, with the light originating mostly from a region broader than the gap itself. Further, Kojima et al. (Kojima et al., 2008) used a high speed video camera to show that expansion of the plasma was complete within $\sim 2 \mu$ s after dielectric breakdown, while the diameter of the crater grew slowly in comparison to the plasma, leading to the suggestion that the plasma diameter was $\sim$ five times larger than the crater diameter under certain conditions, being distinct from conventional plasma expansion models. Similarly, Natsu et al. (Natsu et al., 2006) used a high speed video camera to show that expansion of the plasma was complete within a few $\mu \mathrm{s}$ after dielectric breakdown.

It is noted that there are a variety of approaches for calculating the plasma channel radius in the literature, but with no clear consensus. For example, the time dependent plasma radius equation may be taken as:

$$
R_{\text {plasma }}=R_{p} t^{n}
$$

Where $R_{p}$ is an empirical constant and exponent $\mathrm{n}$ depends on the experimental conditions, with Eubank et al. (Eubank et al., 1993) suggesting $n=0.75$, whilst Izquierdo et al. (Izquierdo et al., 2009) suggest $n=0.2$. Alternatively, the time dependent plasma channel radius equation may be expressed as:

$$
R_{p c}=a I^{m} t_{o n}^{n}
$$

Where $t_{o n}$ is the pulse-on time; $I$ is current, and $a, n$ and $m$ are empirical constants. Ikai and Hashiguchi (Ikai and Hashigushi, 1995) used experimental values for crater radii from single pulse interactions to determine the following empirical relationship, and based on pulse width and discharge current profile can be determined:

$$
R_{p c}=2.04 \times 10^{-3} I^{0.43} t_{o n}^{0.44}
$$

Accordingly, it is recognised that different processing conditions lead to significant differences in the plasma channel radius (Zhang et al., 2014).

With regard to difficulties of measuring the plasma channel reported above and for consistency with many other research, for example, (Das et al., 2003) as well as (Tan and Yeo, 2008) and (Erden, 1983). Therefore, plasma channel radius is assumed to be equal to the crater radius generate by the discharge. An interpolation approach as a function of MATLAB 
software was utilised to estimate the plasma channel radius, based on a wide range of crater measurements as a function of current and pulse-on time, Figure 2.

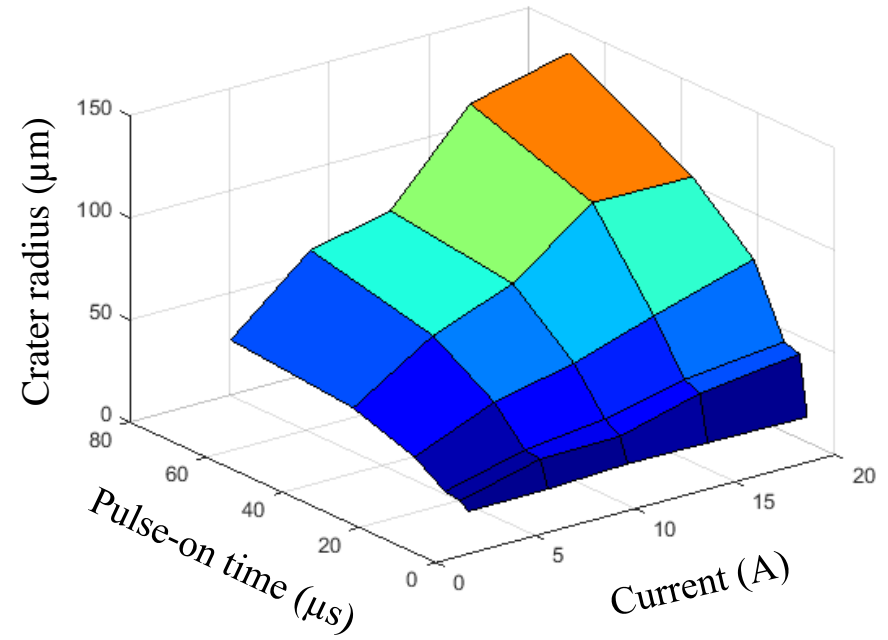

Figure 2 Crater radius as a function of current and pulse-on time obtained experimentally (Table 1).

\subsection{Cooling phase}

Immediately after the pulse-on time, the plasma channel collapses and is replaced by the dielectric fluid. This is accompanied by a sudden drop in pressure which results in the removal of some of the molten material in the form of debris. A cooling phase (pulse-off time) then proceeds allowing for molten material to cool-down and re-solidify, following renewed contact of the crater surface with the dielectric.

Convection boundary conditions may be applied to the surface through Newton's law:

$$
q=h\left(T_{s}-T_{\infty}\right)
$$

Where $q\left(\mathrm{~W} / \mathrm{m}^{2}\right)$ is the convection heat flux; $T_{s}(\mathrm{~K})$ is the initial temperature; $T_{\infty}(\mathrm{K})$ is the dielectric fluid temperature; and $h\left(\mathrm{~W} / \mathrm{m}^{2} . \mathrm{K}\right)$ is the convection heat transfer coefficient which is a function of fluid properties, geometry, surface roughness and the fluid flow pattern (Theodore, 2011). In the present work, fluid flow over a flat plate is assumed to be uniform, at constant velocity, given by:

$$
h=N u_{x} k / L
$$

Where $L(\mathrm{~m})$ is the workpiece length and $N u_{x}$ is the Nusselt number given by:

$$
N u_{x}=0.644 \operatorname{Re}_{x}^{0.5} \operatorname{Pr}^{0.33}
$$

Where $R e$ is the Reynolds number and $P r$ is the Prandtl number, respectively. 


$$
R e_{L}=\rho u_{\infty} L / \mu \quad(12) \quad \text { and } \quad P_{r}=\mu c_{p} / k
$$

Where $u_{\infty}$ is the velocity of the fluid $\left(\mathrm{m}^{2} / \mathrm{s}\right)$ and $\mu$ is the dynamic viscosity of the fluid $(\mathrm{kg} / \mathrm{m} . \mathrm{s})$, for Laminar flow, it is required that $\operatorname{Re}<5 \times 10^{5}$, and $0.6 \leq \operatorname{Pr} \leq 50$ (Theodore, 2011).

\subsection{Methodology}

It is difficult to measure the energy distribution to the anode, cathode and dielectric fluid from the spark process, with temperature and cooling rate directly influencing the microstructural development and hence the physical properties of the modified surface. In the present work, a finite difference method was used to estimate the temperature distribution on the basis of the underpinning thermo-physical properties of the system (Shahri et al., 2016), to simulate the 2D transient heat transfer of a single spark event during EDC. The approach of comparing experimentally determined with theoretically calculated crater radii, as proposed by Xia et al. (Xia et al., 1996) and Zhang et al. (Zhang et al., 2014), was used. This approach allows the percentage of energy transferred to the workpiece to be estimated, to be between 0 and 1 , stepwise 0.01 . In the present approach, when every node on the workpiece under the influence of the spark reaches the melting point, the workpiece is replaced with expressions for a 50:50 composite based on both workpiece and tool electrode material properties. Figure 3 presents a flowchart for this 2D transient heat transfer model, performed using MATLAB. In particular, the model is capable of calculating the rate of cooling of each melt pool, produced by a single spark event, which allows the grain size within the coating layer (crater) to be predicted. 


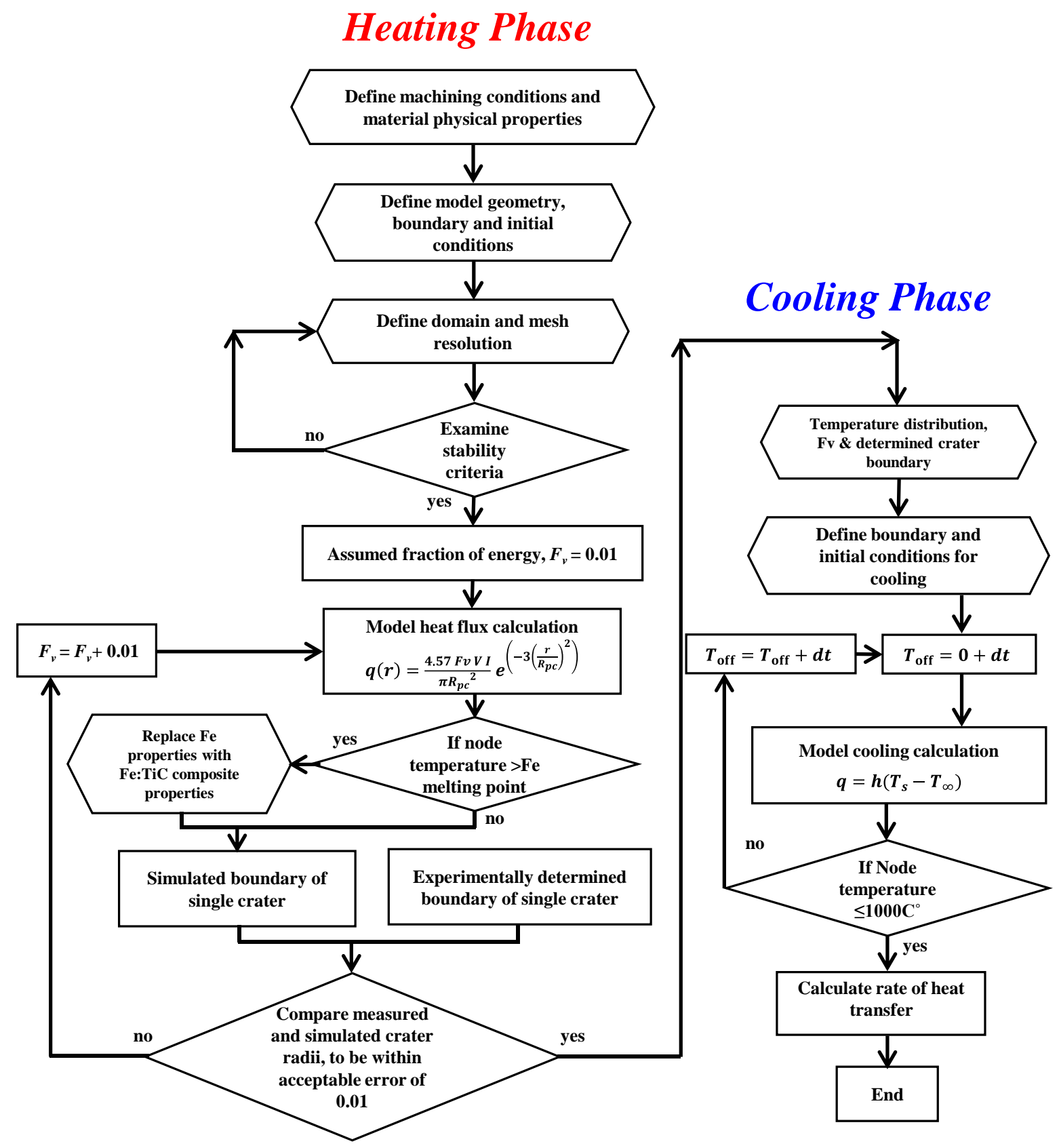

Figure 3 A process flow highlighting the 2D transient heat transfer model.

Experimental work was performed to verify the applicability of this model, using a Mitsubishi EA12V die sinking machine with a semi-sintered $(10 \times 20 \times 100 \mathrm{~mm}) \mathrm{TiC}$ tool electrode. Table 1 presents a summary of the EDC parameters for single spark crater formation $(\sim 0.5$ minutes of processing time) and continuum coating layer formation $(\sim 60$ minutes of processing time): As a function of current and pulse-on time; with fixed values for electrode polarity, voltage and pulse-off time. Sections of 304 stainless steel workpiece material $(20 \times 20 \times 4 \mathrm{~mm})$ were polished to a mirror finish and cleaned with acetone. Table 2 summarises the properties of the workpiece and $\mathrm{TiC}$ tool electrode, respectively. In order to measure the 
gap voltage and record the voltage waveforms for all the processing parameters during EDC, a data acquisition system comprising a PicoScope 4224 (PC Oscilloscope) with differential oscilloscope probes TA041 was used. Thermal conductivity of the dielectric fluid was measured directly using a C-Therm TCi Technologies, averaged over six measurements.

Table 1 EDC machining parameters

\begin{tabular}{|c|c|c|c|c|c|c|c|}
\hline $\begin{array}{c}\text { Working } \\
\text { parameters }\end{array}$ & $\begin{array}{c}\text { Current } \\
(\mathbf{A})\end{array}$ & Pulse-on $(\boldsymbol{\mu s})$ & $\begin{array}{c}\text { Pulse- } \\
\text { off } \\
(\boldsymbol{\mu s})\end{array}$ & $\begin{array}{c}\text { Voltage } \\
(\mathbf{V})\end{array}$ & $\begin{array}{c}\text { Tool } \\
\text { electrode } \\
\text { polarity }\end{array}$ & $\begin{array}{c}\text { Electrode } \\
\text { material }\end{array}$ & $\begin{array}{c}\text { Machining } \\
\text { time (min) }\end{array}$ \\
\hline Description & $2,6,10,14,19$ & $2,4,8,16,32,64$ & 256 & 320 & negative & TiC & $60 \& 0.5$ \\
\hline
\end{tabular}

Table 2 Material properties of the workpiece and tool electrode

\begin{tabular}{|c|c|c|c|c|c|}
\hline & $\begin{array}{c}\text { Density } \\
\left(\mathbf{k g} / \mathbf{m}^{\mathbf{3}}\right)\end{array}$ & $\begin{array}{c}\text { Thermal } \\
\text { conductivity } \\
(\mathbf{W} / \mathbf{m} . \mathbf{K})\end{array}$ & $\begin{array}{c}\text { Specific } \\
\text { heat } \\
\text { capacity } \\
(\mathbf{J} / \mathbf{k g} . \mathbf{K})\end{array}$ & $\begin{array}{c}\text { Latent } \\
\text { heat of } \\
\text { fusion } \\
(\mathbf{J} / \mathbf{k g})\end{array}$ & $\begin{array}{c}\text { Melting } \\
\text { point } \\
(\mathbf{K})\end{array}$ \\
\hline $\mathbf{3 0 4 - S S}$ & 7,905 & 15 & 510 & 272,500 & 1,698 \\
\hline $\mathbf{T i C}$ & 4,910 & 21.5 & 5,565 & $1,160,000$ & 3,478 \\
\hline
\end{tabular}

EDC processed samples were cross-sectioned using an ATA Brillant 220 cutting machine, mounted, polished and washed with acetone, and etched with Krolls reagent ( $2 \mathrm{ml} \mathrm{HF}, 3 \mathrm{ml}$ $\mathrm{HNO}_{3}$ and $500 \mathrm{ml}$ distilled water), to delineate the TiC distribution within the coating. Metallurgical analyses of the workpiece surfaces and coatings were performed using scanning electron microscopy (SEM) (FEI XL30) and energy dispersive X-ray spectroscopy (EDS) (Oxford Instruments, INCA).

\section{Results}

\subsection{Gap voltage measurement}

The gap voltage was measured for each set of processing parameters. Figure 4 presents examples of open gap voltages, as measured under three different discharge conditions (constant current of $10 \mathrm{~A}$ : and 8, 32 and $64 \mu$ s pulse-on times), illustrating details of the rapidly changing voltage (12.5 ns sample interval and $80 \mathrm{MS} / \mathrm{s}$ sampling rate). In each case, a capacitor charges until it reaches the applied voltage, then the voltage drops suddenly to a steady state value at which point discharge occurs, and this value is maintained for the whole duration of the discharge, then decreases when the discharge ceases. The gap voltage was observed to vary in the range $25-35 \mathrm{~V}$, for variable conditions of current ( 2 to $19 \mathrm{~A}$, for a fixed pulse-on time of $8 \mu \mathrm{s}$ ); and variable conditions of pulse-on times ( 2 to $16 \mu \mathrm{s}$, for a fixed current of $10 \mathrm{~A}$ ). Accordingly, a value of $30 \mathrm{~V}$ was used as the gap voltage in the modelling, for the case of these 
processing parameters. However, it was observed that the gap voltage decreased significantly, to $23 \mathrm{~V}$ and $18 \mathrm{~V}$, with increasing pulse-on times of $32 \mu \mathrm{s}$ and $64 \mu \mathrm{s}$, respectively, necessitating adjustment to the modelling voltage in these cases. Furthermore, it was observed that the agitation delay time for discharge varied, for each set of processing parameters.

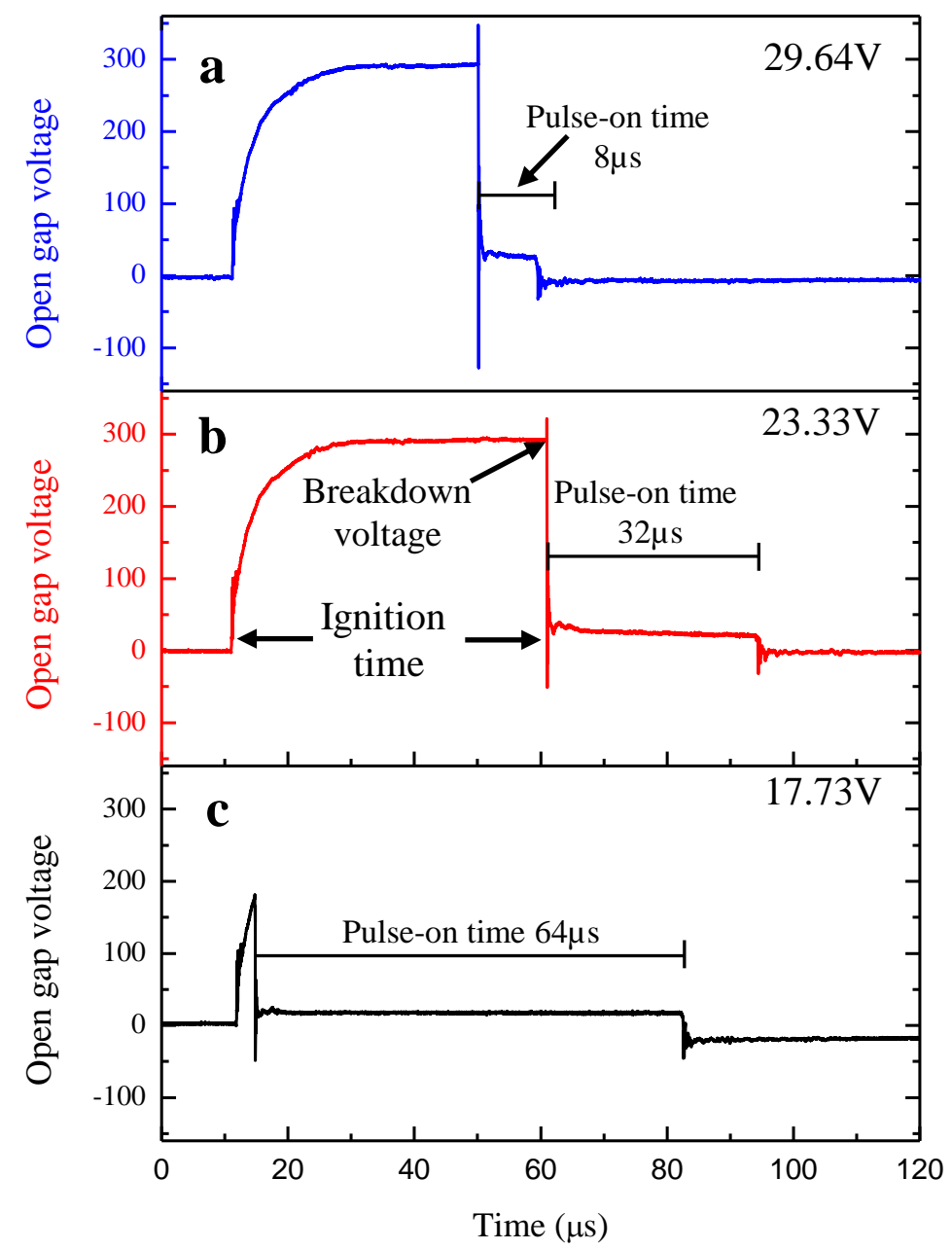

Figure 4 Waveforms associated with coatings produced using a TiC tool electrode and a 304 stainless steel workpiece, with negative polarity for pulse-on times of: a) $8 \mu \mathrm{s}$, b) $32 \mu \mathrm{s}$ and c) $64 \mu \mathrm{s}$ (fixed $10 \mathrm{~A}$ current).

\subsection{Code validity and fraction of energy transferred to the workpiece}

Figure 5 presents a comparison of the fraction of energy transferred to the workpiece during EDC processing, as predicted by the present model (red lines), based on estimates for $F_{v}$ obtained during EDM processing, as reported by Singh (Singh, 2012) (blue lines) and Shabgard and Akhbari (Shabgard and Akhbari, 2016) (black lines), as a function of increasing current and pulse-on time. The energy distribution ratio into the workpiece varied between $17 \%$ and 
$23 \%$ with increasing current (fixed pulse-on time of $8 \mu \mathrm{s}$ ), whilst a significant increase in the amount of energy transferred to the workpiece, up to $\sim 50 \%$ was associated with an increase in pulse-on time (fixed current of $10 \mathrm{~A}$ ). The high increase in fraction of energy transferred, for pulse-on conditions of 32 and $64 \mu \mathrm{s}$, was attributed to the drop in gap voltages, to 23 and $18 \mathrm{~V}$, respectively. Overall, the values of $F_{v}$ are in good general agreement with previous reports such as (Singh, 2012) and (Shabgard and Akhbari, 2016), but are slightly higher, which probably reflects the differences in the EDC mechanisms of surface modification, as workpiece material is replaced / alloyed with tool electrode material, being distinct from material removal during EDM processing.
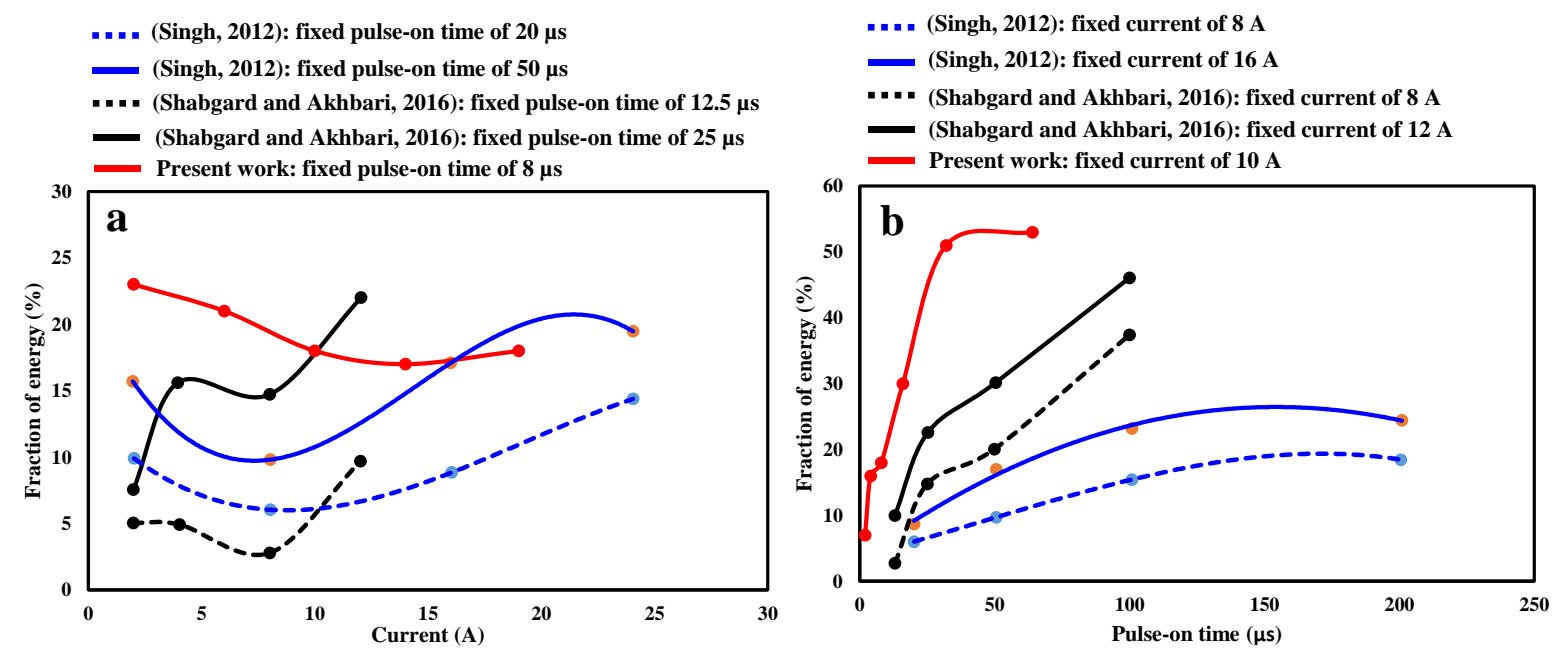

Figure 5 Fraction of energy transferred to the workpiece, compared to literature (Singh, 2012) and (Shabgard and Akhbari, 2016) as function of increasing: a) current and b) pulse-on time.

\subsection{Heat distribution}

Simulated results for temperature distribution into the workpiece, as a consequence of single spark events, as a function of increasing current and pulse-on time, are shown in Figure 6. The minimum temperature attained was determined to be $\sim 13,000 \mathrm{~K}$ under low energy processing parameters (i.e. $2 \mathrm{~A} / 8 \mu \mathrm{s}$ and $10 \mathrm{~A} / 2 \mu \mathrm{s}$ ). With increasing current (4 to $19 \mathrm{~A}$, for fixed pulseon time of $8 \mu \mathrm{s}$ ), the temperature was found to vary between $\sim 17.5 \times 10^{3}-20 \times 10^{3} \mathrm{~K}$; whilst for increasing pulse-on time ( 8 to $64 \mu \mathrm{s}$, for a fixed current of $10 \mathrm{~A}$ ), temperatures of $\sim 20 \mathrm{x}$ $10^{3} \mathrm{~K}$ reducing to $\sim 16 \times 10^{3} \mathrm{~K}$ were achieved. 

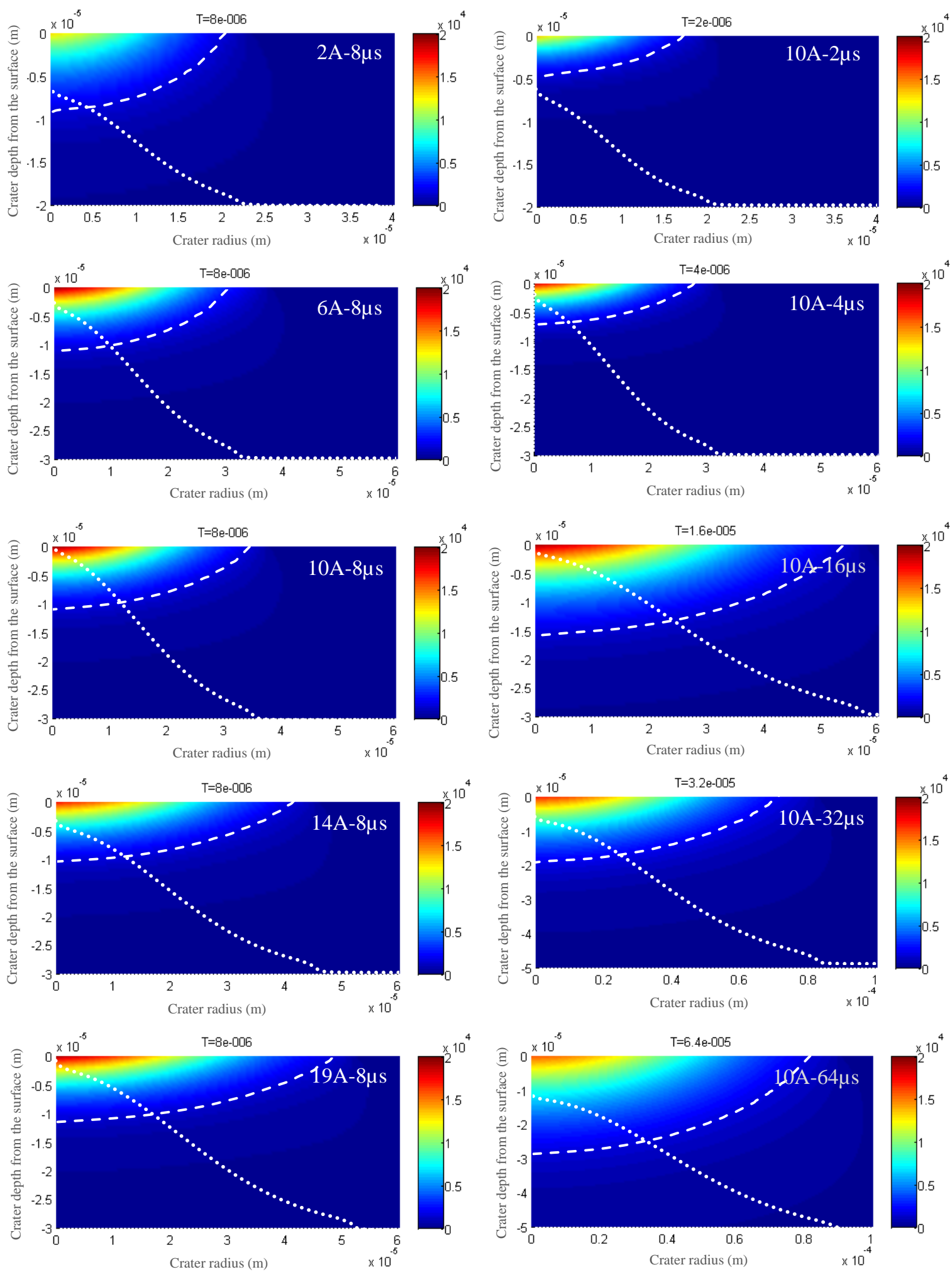

Figure 6 MATLAB simulations showing heat distribution into the workpiece at the end of the 'pulse-on' stage; along with the temperature distribution across the top surface (dotted white line) and the boundary of molten material with the bulk substrate (dashed white line).

Each dotted white line represent the radial temperature distribution across the top surface of the workpiece, from the centre of a single discharge, which acts to define the size of the crater. 
The highest temperature established at the centre gradually decreases with distance from the origin, reflecting the Gaussian distribution of the heat flux equation. Hence, maximum energy was transferred at the centre, with decreasing power density towards the periphery. The dashed white line represents the consequent boundary of molten material with the bulk substrate. It is considered that the neighbouring workpiece surface that does not interact directly with the plasma channel is largely unaffected, due to short pulse-on time, and hence does not change significantly in temperature.

\subsection{Crater diameter}

Representative craters for each set of processing parameters were identified using SEM (Figure 7) with reported sizes based on an average of 30 measurements, as determined using ImageJ, Table 3. The edges of individual craters produced by discrete spark events could be readily identified. Overlapping craters and craters created from abnormal discharges were discounted. Average crater sizes ranged from 41 to $96 \mu \mathrm{m}$ with increasing current from 2 to 19 A (fixed pulse-on time of $8 \mu \mathrm{s}$ ); and from 35 to $165 \mu \mathrm{m}$ with increases in the pulse-on time from 2 to 64 $\mu$ s (fixed current of $10 \mathrm{~A}$ ), which reflects the general trend of increasing input energy (Algodi et al., 2016).

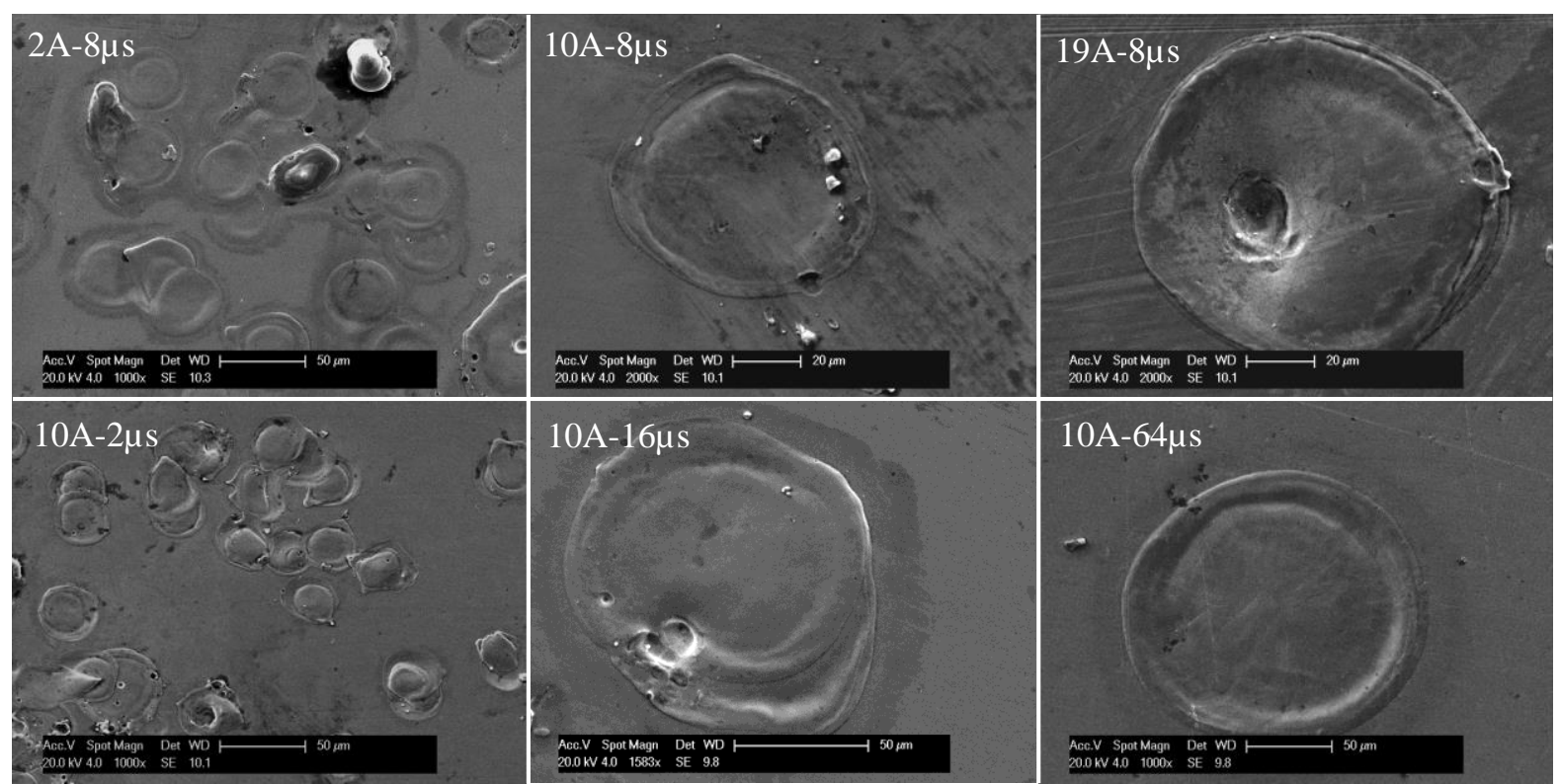

Figure 7 Plan view SE images of craters created from single spark events, at the start of template coating. Average crater sizes increase with increasing pulse energy.

Table 3 Average crater sizes $(n=30)$ as a function of processing conditions

\begin{tabular}{|l|l|l|l|l|l|l|l|l|l|l|l|r|}
\hline & \multicolumn{4}{|c|}{ Current / A } & \multicolumn{5}{c|}{ Pulse-on time / $\mu$ s } \\
\hline & 2 & 6 & 10 & 14 & 19 & 2 & 4 & 8 & 16 & 32 & 64 \\
\hline
\end{tabular}




\begin{tabular}{|c|c|c|c|c|c|c|c|c|c|c|c|c|}
\hline $\begin{array}{c}\text { Mean crater size / } \\
\boldsymbol{\mu m}\end{array}$ & $\mathbf{4 1}$ & $\mathbf{6 0}$ & $\mathbf{6 9}$ & $\mathbf{8 3}$ & $\mathbf{9 6}$ & $\mathbf{3 5}$ & $\mathbf{5 7}$ & $\mathbf{6 9}$ & $\mathbf{1 0 7}$ & $\mathbf{1 5 1}$ & $\mathbf{1 6 5}$ \\
\hline$\sigma$ & 4.3 & 4.7 & 5.0 & 8.6 & 8.7 & 5.6 & 11.8 & 5.7 & 7.8 & 14.3 & 16.5 \\
\hline
\end{tabular}
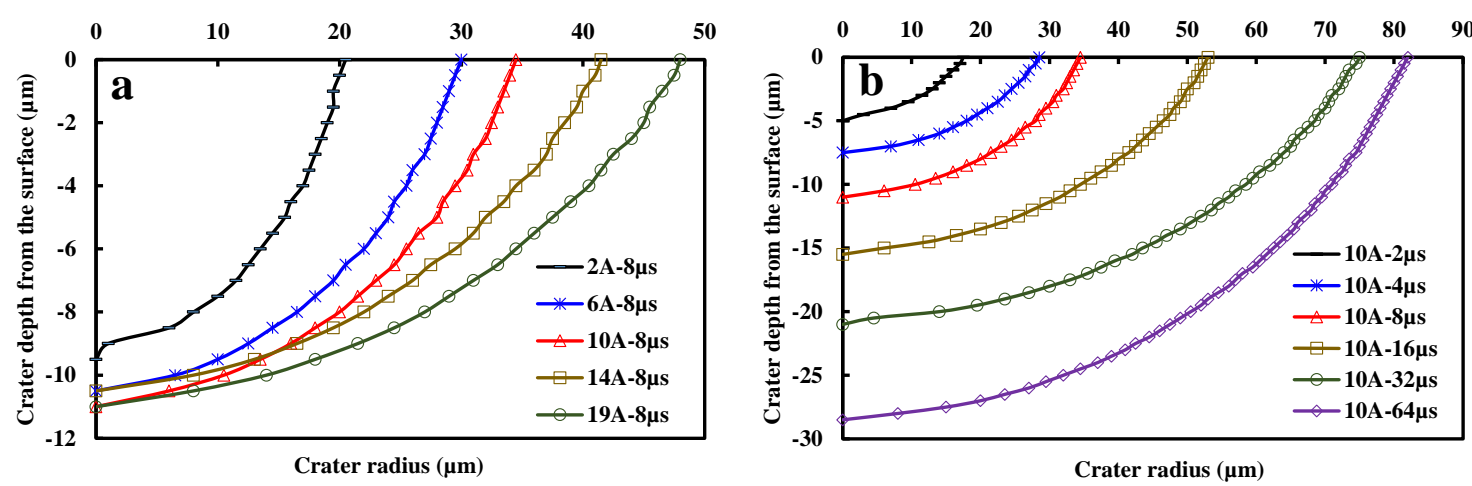

Figure 8 Simulated crater boundaries into the workpiece as a function of increasing: a) current and b) pulse-on time.

Simulated crater profiles, delineating the boundary between the melt pool and the bulk workpiece, as a function of current and pulse-on time, are presented in Figures 8a and b. Crater diameter was predicted to increase significantly with increasing current (for fixed pulse-on time of $8 \mu \mathrm{s}$ ), but without significant change in melt pool depth (Figure 8a); whilst increasing the pulse-on time (for fixed current of 10A) resulted in an increase in both crater width and depth (Figure 8b) (Maradia et al., 2015).

\subsection{Layer thickness}

Figure 9 presents representative high magnification BSE images of the ED processed samples in cross-section geometry, providing detailed insight into the microstructural development of the coatings, confirming the formation of a metal matrix composite (MMC) of variable $\mathrm{TiC} /$ Fe composition, as a function of the processing conditions (Algodi et al., 2016). Representative localised compositions, as determined by EDS, are summarised in Table 4 (Figures 9b:1-3, c:46). Regions of enhanced TiC (Figures 9, arrowed), originating from the tool electrode, appear dark (locally averaged composition) within such BSE images, due to the lower atomic number of Ti compared to Fe. Coatings produced under the low energy conditions of $2 \mathrm{~A}(8 \mu \mathrm{s})$ and 10 A $(2 \mu \mathrm{s})$ show a non-uniform distribution of TiC throughout the coating (Figures $9 \mathrm{a}$ and $\mathrm{b}$ ), reflecting a lower level of intermixing between workpiece and transferred tool electrode material. Coatings produced under conditions of increasing current (10 - 19 A for a fixed pulseon time of $8 \mu \mathrm{s}$ ) exhibit a higher amount and more regular distribution of $\mathrm{TiC}$ throughout the coating, but with a much more complicated, intermixed microstructure (Figures 9c and 9e), 
being attributable to the electrode condition, complexities of the melting mechanism, material re-deposition and intermixing with the substrate during multiple discharges (Murray et al., 2016).

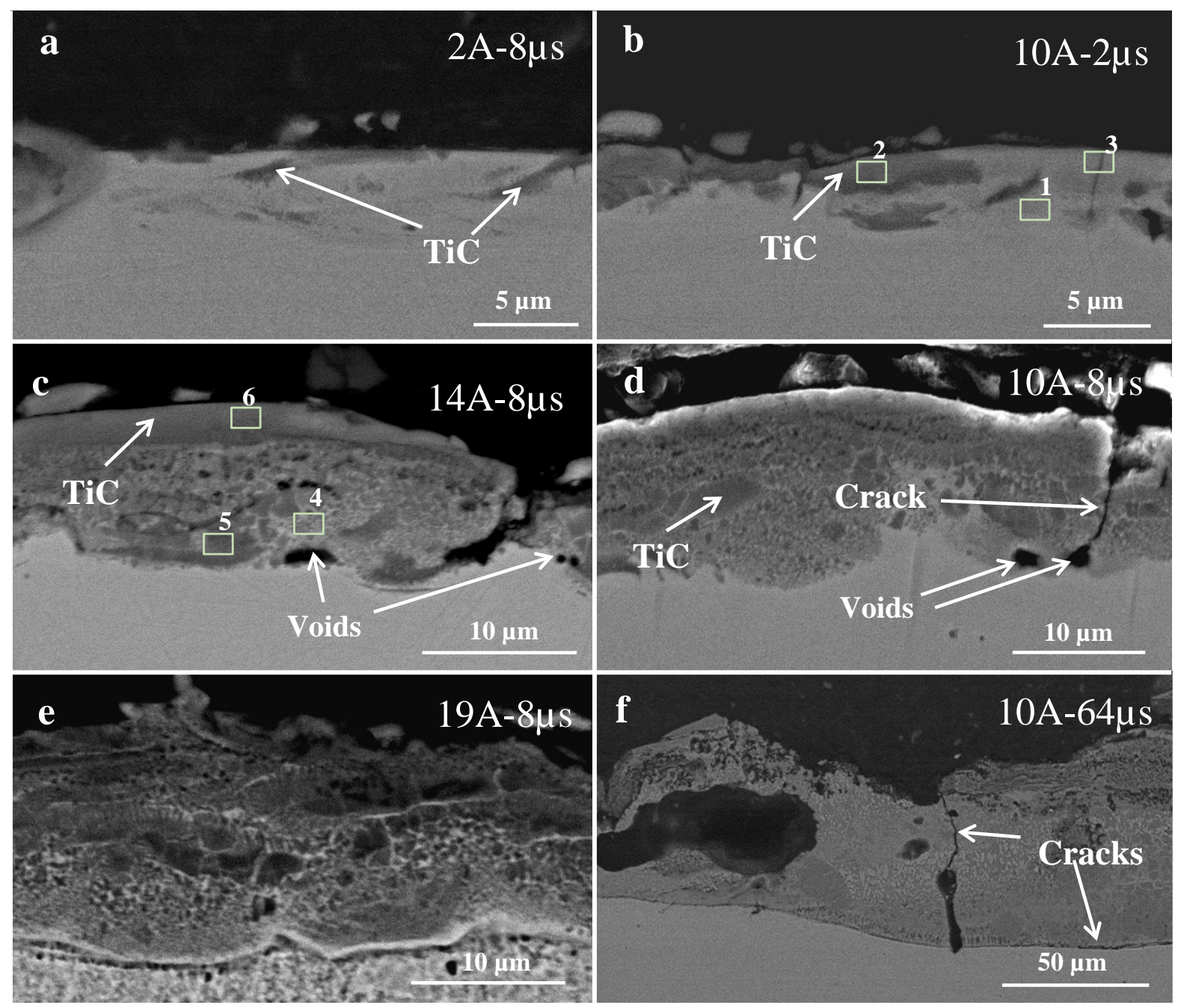

Figures 9 SE images of ED processed coatings, viewed in cross-section: (a,c,e) for fixed pulse-on time of $8 \mu$ s as a function of increasing current; and (b,d,f) for fixed current of $10 \mathrm{~A}$ as a function of increasing pulse-on time. (b:1-3; and c:4-6) Representative localised compositions, determined by EDS, are summarised in Table 4.

Table 4: Elemental distribution

\begin{tabular}{|c|c|c|c|c|c|c|c|c|c|}
\hline & \multicolumn{5}{|c|}{ Element (wt\%) } & \multicolumn{4}{c|}{ Element (wt\%) } \\
\hline $\begin{array}{c}\text { Fig 9b } \\
\text { Region }\end{array}$ & Ti & Fe & C & Cr & $\begin{array}{c}\text { Fig 9c } \\
\text { Region }\end{array}$ & Ti & Fe & C & Cr \\
\hline 1 & $\mathbf{6 . 1 7}$ & $\mathbf{6 1 . 7 5}$ & $\mathbf{1 3 . 2 9}$ & $\mathbf{1 4 . 6 2}$ & 4 & $\mathbf{3 2 . 1 9}$ & $\mathbf{3 5 . 8 1}$ & $\mathbf{1 8 . 7 3}$ & $\mathbf{1 0 . 1 7}$ \\
\hline 2 & $\mathbf{3 8 . 7 7}$ & $\mathbf{1 1 . 6 3}$ & $\mathbf{3 3 . 6 0}$ & $\mathbf{7 . 7 2}$ & 5 & $\mathbf{3 7 . 5 3}$ & $\mathbf{2 5 . 0 6}$ & $\mathbf{1 7 . 7 8}$ & $\mathbf{8 . 9 6}$ \\
\hline 3 & $\mathbf{2 1 . 4 2}$ & $\mathbf{4 0 . 6 4}$ & $\mathbf{2 7 . 5 9}$ & $\mathbf{7 . 4 8}$ & 6 & $\mathbf{5 6 . 7 9}$ & $\mathbf{7 . 1 3}$ & $\mathbf{3 2 . 2 7}$ & $\mathbf{3 . 8 1}$ \\
\hline
\end{tabular}

Simulations of crater formation from single spark events during EDM processing provide information on material removal rate and the thickness of the recast layer, to help refine the process. Similarly, simulations of single spark events during EDC processing, as performed 
here, provide for improved understanding of crater development and the layer formation process in terms of resultant microstructure and thickness. Figure 10 presents a comparison of simulated crater depths from single spark events, with experimentally determined EDC layer thicknesses (after 60 minutes of processing, corresponding to the overlap of $~ 185$ spark events (Algodi et al., 2016)), as a function of increasing current and pulse-on time. The key point being that there is a strong correlation between crater depth and developed coating thickness, consistent with EDC being a sequential replacement process for near surface material. A slight increase in simulated crater depth with increasing current (2 - $10 \mathrm{~A})$ was returned (Figure 10a), reflecting a fairly consistent fraction of energy into the workpiece (Figure 5a); whilst increasing the pulse-on time led to a significant increase in crater depth, commensurate with an increase in layer thickness (Figure 10b), reflecting the increased energy imparted to the workpiece (Figure 5b). It is noted that crater depth and layer thickness followed a very similar trend with increasing pulse-on times from 2 to $16 \mu \mathrm{s}$, whilst there was a higher discrepancy between simulated and experimentally determined values for longer pulse-on times of 32 and $64 \mu \mathrm{s}$, reflecting a greater variation in crater sizes under higher energy processing conditions.
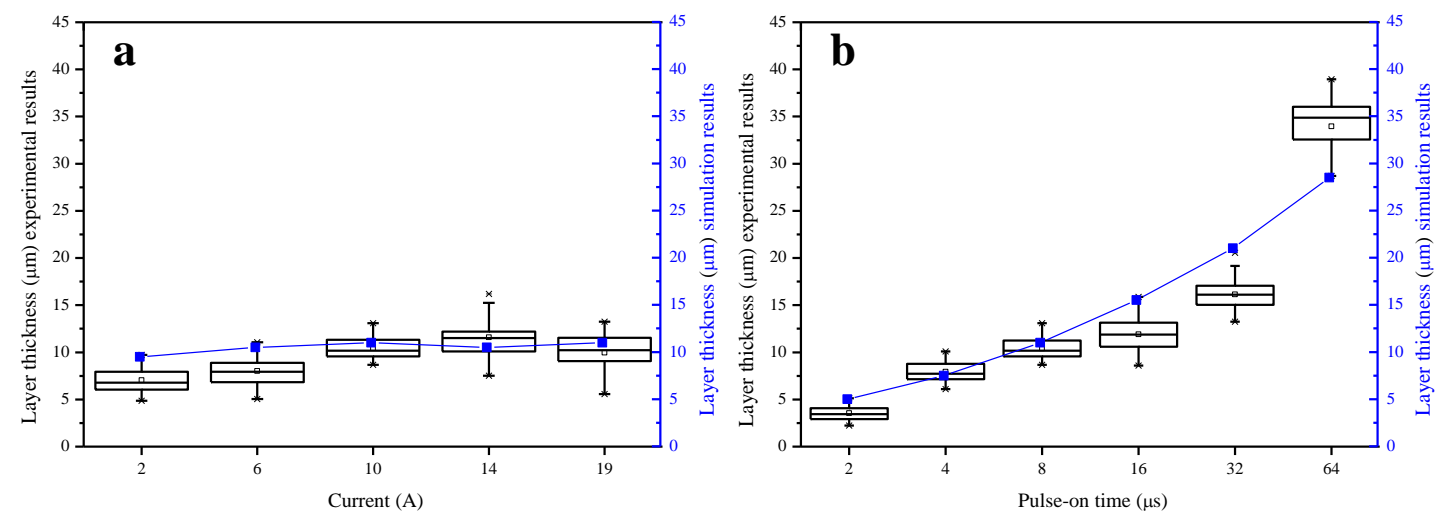

Figure 10 Comparison of simulated crater depth from single spark event with experimentally determined EDC layer thicknesses, as a function of increasing: a) current and b) pulse-on time.

\subsection{Cooling phase and coating microstructural development}

Figure 11 presents more detailed BSE images of the $\mathrm{Fe} / \mathrm{TiC}$ cermet coatings, produced under conditions of 8 and $64 \mu$ s (fixed current of $10 \mathrm{~A}$ ), respectively, in order to illustrate the variability of the fine scale microstructure. For the former $(8 \mu \mathrm{s})$, the microstructure comprised a band of very fine grained material at the surface (Figure 11b - Region I); a thin, transitional region of columnar grains (Figure 11d - Region II); a band of equiaxed, coarser TiC grains within the Fe matrix (Figure 11d - Region III); and another band of very fine grained material next to the coating/substrate interface (Figure 11c - Region IV). The development of this 
microstructure was attributed to localised differential cooling rates, as determined by heat flow back into the dielectric oil and into the substrate, on the time scale of an individual discharge.

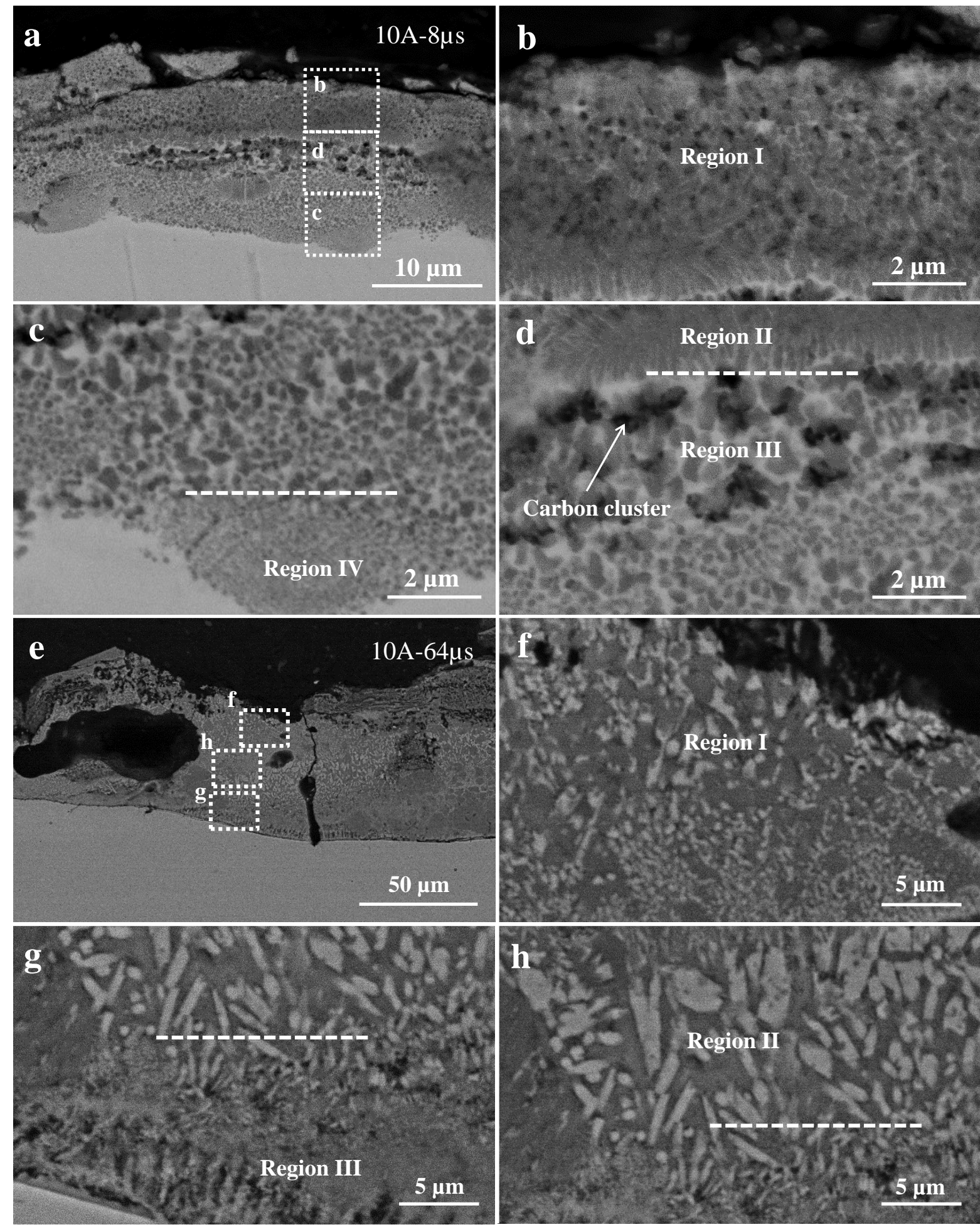

Figure 11 BSE images of the developed cermet coating microstructures in cross-section geometry, processed under conditions of: a-d) 10 A, $8 \mu \mathrm{s}$; and e-h) 10 A, $64 \mu \mathrm{s}$.

Similarly, the latter (64 $\mu \mathrm{s})$ showed the development of a banded microstructure with generally larger grain sizes, reflecting the increased pulse-on time and energy into the system, and the 
consequent longer time taken for cooling and recrystallisation. The near surface region was characterised by relatively large grains (Figure 11f - Region I); an inner banded structure of columnar grains (Figure $11 \mathrm{~h}$ - Region II); and a dendritic structure next to the coating/substrate interface (Figure 11g - Region III) (Zhitnyak et al., 2016). Increased thickness of the coating layer was associated with increased levels of cracking through the coating and at the coating/substrate interference (Figure 9f and Figure 11e).

Figures $12 \mathrm{a}$ and $\mathrm{b}$ present the average rate of change of temperature at the surface of a single cermet crater centre, as a function of increasing current (for a fixed pulse-on time of $8 \mu \mathrm{s}$ ) and increasing pulse-on time (for a fixed current of $10 \mathrm{~A}$ ), respectively. The rate of heat transfer varied for these sample sets, with the highest value of $\sim 6.8 \times 10^{8} \mathrm{~K} / \mathrm{s}$ returned for samples produced under conditions of low pulse-on time of $2 \mu \mathrm{s}(10 \mathrm{~A})$; whilst a long pulse-on time of $64 \mu \mathrm{s}(10 \mathrm{~A})$, or an increase in current (> $10 \mathrm{~A})$, were associated with lower values of cooling rate. Since the flow of dielectric fluid was maintained constant, this variation in heat flow was attributed to differences in the melt pool volume and its initial temperature after the pulse-on time.
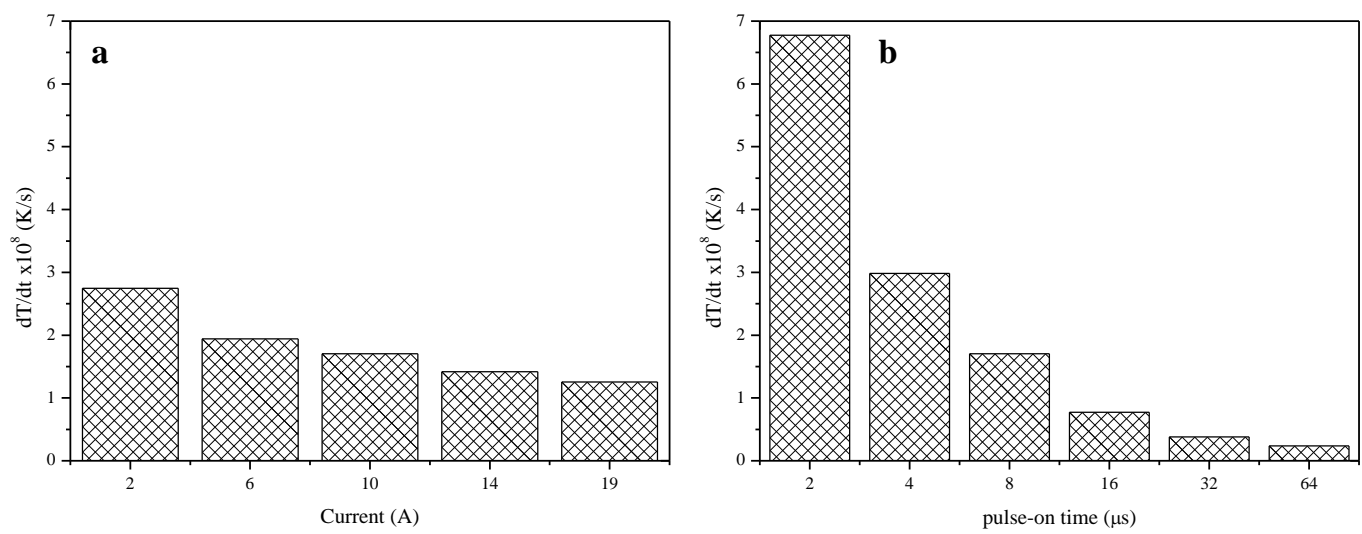

Figure 12 Average surface simulated cooling rate for a single TiC crater deposit as a function of: a) Current (fixed pulse-on time of $8 \mu \mathrm{s}$ ) and b) Pulse-on time (fixed current of $10 \mathrm{~A}$ ).

To better understand the microstructural formation processes of both individual craters and layer cermet coatings comprising many sequentially deposited craters, temperature profiles at different depths into a crater, as a function of increasing time, where determined. Figure 13 shows a depiction of the microstructure generated within a crater processed under conditions of $10 \mathrm{~A}$ current and $8 \mu \mathrm{s}$ pulse-on time (Figure 9d and 11a), alongside temperature-time simulation with each curve representing a node located at different depths ( $1 \mu \mathrm{m}$ pitch) into the centre of the crater; i.e. from the oil-flow/surface interface to the melt/solid (crater/workpiece) 
interface. It is noted that the temperature of the near surface molten material decreases sharply, reducing to $\sim 4 \times 10^{3} \mathrm{~K}$ within $\sim 10 \mu$ s of the end of the pulse-on time, followed by a lower cooling rate. The resultant banded microstructure within the crater is defined by the competing heat transfer processes, with rapid cooling of near surface material governed by convection within the flowing dielectric oil, whilst initial gentle heating combined with slightly slower cooling rates in the vicinity of the melt/solid interface $(\sim 3 \mu \mathrm{m}$ from the bottom of the crater) are governed by conduction into the substrate. Hence, it is evident that the cooling phase has two distinct stages, with rapid non-uniform cooling within the first $\sim 10-20 \mu$ s leading up to the onset of TiC crystallisation $(\sim 3.16-3.25) \times 10^{3} \mathrm{~K}$, followed by a second more uniform stage of heat loss up to $\sim 100 \mu \mathrm{s}$, leading up to the onset of Fe matrix solidification $(\sim 1.4$ 1.45) $\times 10^{3} \mathrm{~K}$.

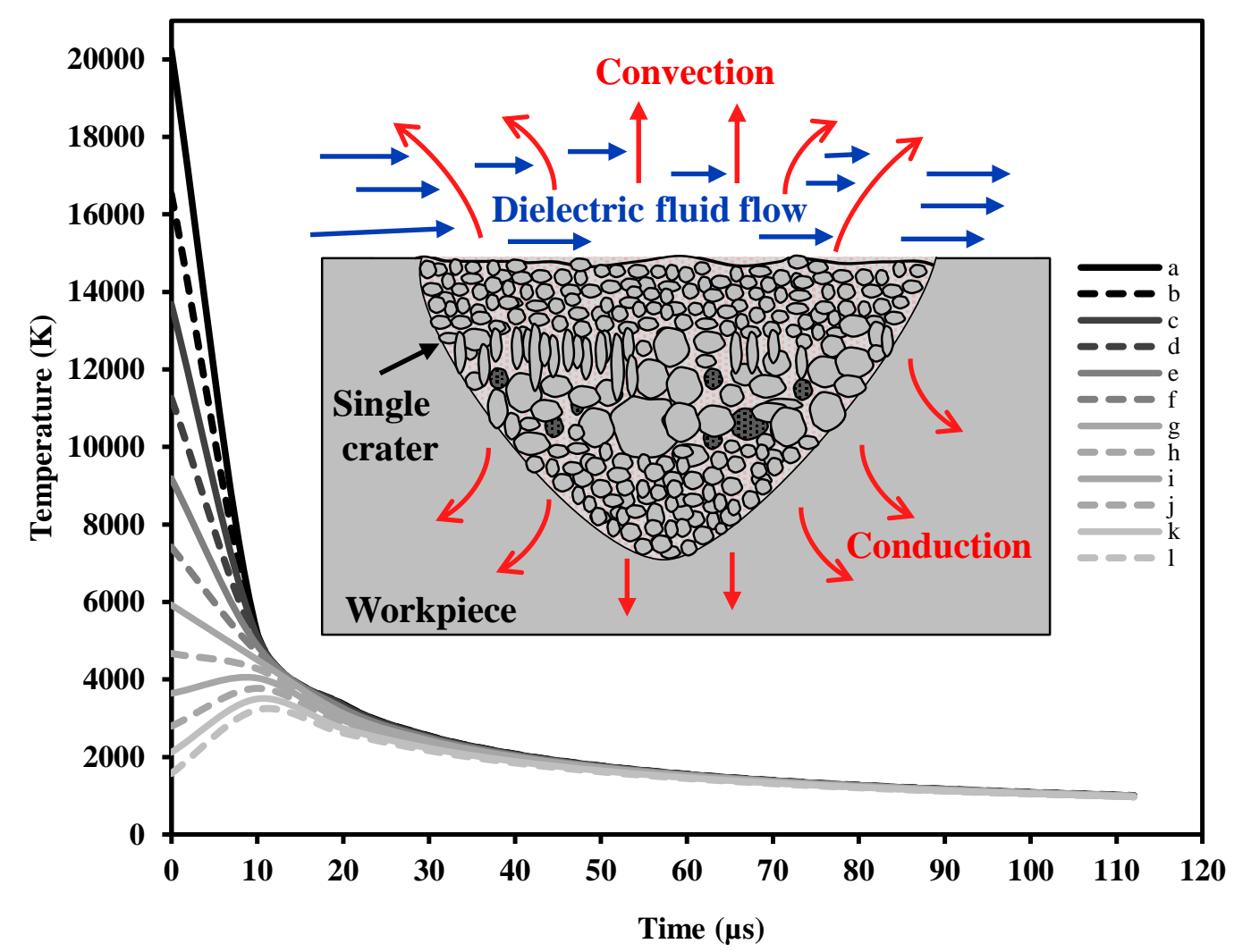

Figure 13 Cooling profiles as a function of increasing time (pulse-off), each line representing a node located at the crater centre (a-1) from the oil-flow/surface interface to the melt/solid with $1 \mu \mathrm{m}$ pitch.

\section{Discussion}

The fraction of total discharge energy transferred to the workpiece is an important factor determining temperature distribution within the modified layer; the modelling of which allows for prediction of the developed microstructure and correlation with layer mechanical properties 
(Algodi et al., 2016). The fraction of energy transferred to the workpiece, $F_{v}$, is defined ultimately by the discharge voltage, current and pulse-on time. Figure 5a illustrates that an increase in current, from 2 to $19 \mathrm{~A}$, for a fixed pulse-on time of $8 \mu \mathrm{s}$, having a low impact on $F_{v}$, and this is attributed to the instability of the heat source. Under conditions of short pulseon time, discharge occurs at very high frequency, resulting in inadequate time for conduction of energy and hence insignificant impact of current (Shabgard and Akhbari, 2016). Conversely, Figure $5 \mathrm{~b}$ illustrates increasing $F_{v}$ to the workpiece with increasing pulse-on time from 2 to 64 $\mu$ s (for a fixed current of $10 \mathrm{~A}$ ), being attributable to the effects of a relatively steady heat source with sufficient time for conduction. No significant change in $F_{v}$ at high pulse-on times of $\sim 32-64 \mu$ s occurs (Figure $5 b$, red line) because additional energy supply is lost to maintain the plasma channel, and hence energy transfer to the workpiece becomes limited (Singh, 2012). Singh and Shukla (Singh and Shukla, 2012) report similarly that a further increase in pulse-on time does not give significant erosion during EDM, with additional energy supplied being lost to maintain the plasma channel.

It is evident that the values for $F_{v}$, predicted using the current model, are close to the experimental EDC data and in good agreement with other studies, including (Singh, 2012) and (Shabgard and Akhbari, 2016) (Figure 5), reflecting the incorporation of real processing conditions, such as the Gaussian distribution of the heat source, along with latent heat of fusion and the cermet material properties. However, it is noted that the modelling of EDC processes returns slightly higher values for $F_{v}$, as compared to EDM. This is attributed to the difference between coating and machining processes, with EDC acting to replace and intermix near surface material rather than remove material, with a decrease in the heat carried away by debris leading to an increase of heat conducted into the workpiece (Okada et al., 2000).
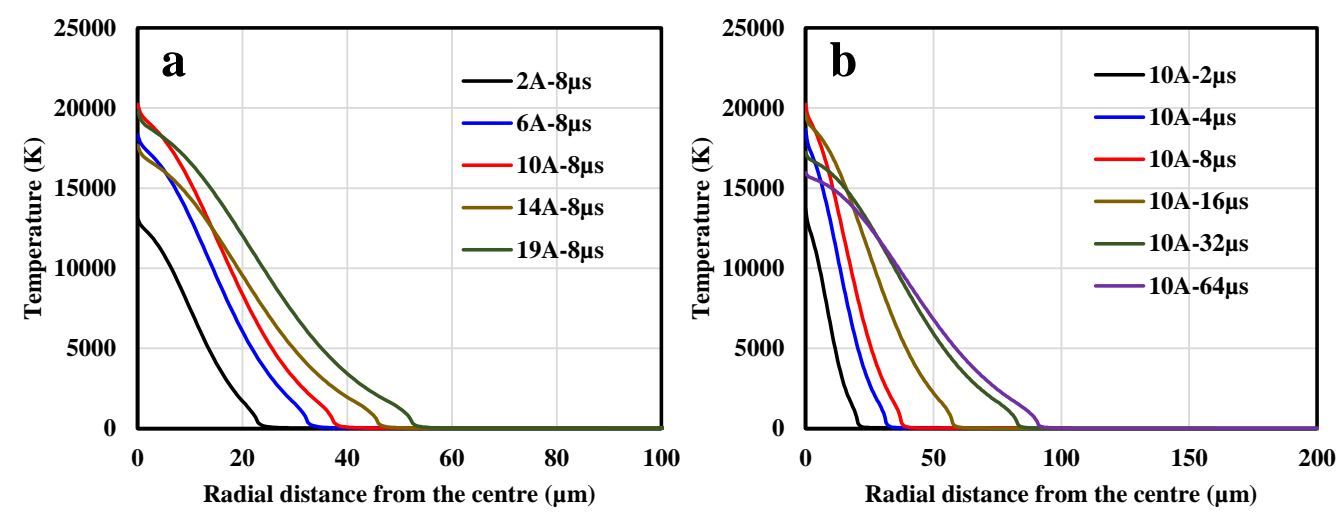

Figure 14 Radial temperature profiles along the top surface of the workpiece as functions of: a) increasing current and b) pulse-on time. 
Figures $14 \mathrm{a}$ and $\mathrm{b}$ (extracted from Figure 6) present simulated temperature profiles across the top surface of the workpiece as a function of current and pulse-on time, respectively, demonstrating increases in the size of the heat affected region with increasing the current and pulse-on time, however, maximum temperature does not have the same trend, reflecting the increasing size of the plasma channel. A similar effect was reported by Xie et al (XIE et al., 2011) for EDM simulations of Ti-alloys.

Further, the modelling of crater depth (Figure 10) showed good agreement with experimental data for the overall EDC layer thickness. The increase in crater depth with increasing pulse-on time (Figure 10b) is related directly to increasing $F_{v}$ and correlates with the depth of initially formed craters from single spark events, being attributable to the more effective transfer of heat into the bulk. Small variations between the simulated and measured crater depths (and layer thicknesses) for conditions of high pulse-on time $(32-64 \mu \mathrm{s})$ is attributed to the high variability of crater sizes (Table 3), attributed to fluctuating average gap voltages. Hence, crater dimensions are dependent primarily upon heat input during discharge and the time required to create each melt pool.

The EDC processing conditions of $10 \mathrm{~A}$ and $8 \mu$ s produced colonies of very fine grained equiaxed TiC within an Fe matrix near the coating surface and close to the melt pool / substrate interface, along with an intermediate band of larger equiaxed and columnar grains containing segregated clusters of carbon (Figures 11a-d; (Algodi et al., 2016)), being characteristic of a very rapid cooling process and indicative of the initiation of crystallisation at both the surface and the melt pool / substrate interface. During the pulse-on time, TiC particles from the tool electrode melt and fuse with the workpiece melt pool, whilst the process of solidification starts at the end of the discharge. The TiC melting point is higher than that of $\mathrm{Fe}$ and hence it is anticipated that $\mathrm{TiC}$ particles develop in advance of Fe matrix formation. Subtle variations in localised grain sizes simply reflect variations in localised composition and heat flow, mediated by conduction into the substrate and convection into the dielectric oil.

This description of ED coating development is consistent with the predictions of the simulations based on heat transfer into the workpiece. A steep drop in temperature was predicted for the near surface of the melt pool, to $\sim 4 \mathrm{x} 10^{3} \mathrm{~K}$, during the first $\sim 10 \mu \mathrm{s}$ (Figure 13), which is still above the melting point of TiC. At the same time a gradual rise in temperature was predicted in the vicinity of the melt pool / substrate interference. Thereafter, a more generalised, homogeneous cooling process occurred, resulting in the onset of the solidification process. Lower average values for the rate of change of temperature were predicted for samples 
produced under conditions of high pulse-on time of $64 \mu \mathrm{s}$ (Figure 12b), consistent with the development of more dendritic $\mathrm{TiC} / \mathrm{Fe}$ cermet morphologies observed at the melt pool / substrate interface (Figures 11e-h), being consistent with high thermal input energy and a relatively low cooling rate in this case (Sahoo et al., 2016), whilst columnar grained structures were again found in the middle of this coating.

EDC has received attention given its potential advantages including the ability to consecutively machine material while depositing a coating in the same process, without needing further apparatus or post-processing. Secondly, the process takes advantage of the ability of EDM to create complex shapes using an inverted form tool electrode, and hence the coating process can easily be applied to complex components. Since EDC is capable of producing coatings from hard, high melting point materials such as ceramics, which may be difficult to process by other means, the technique has excellent potential for the production of hard-wearing coatings to enhance the lifetime of components. This work has opened up the possibility to extend the model to include different material types and dielectric media. This is essential for developing new process methodologies.

\section{Conclusion}

A theoretical model has been developed to predict the amount of energy transferred into the workpiece during the EDC processing of cermet coatings. 2D transient heat transfer principles solved by the finite difference method enabled coating thicknesses and microstructures to be predicted and validated against experimental observations. The modelling demonstrated that the fraction of energy imparted into the workpiece from each spark event is a critical consideration for ED processing and varies as a function of process conditions. The effective amount of energy transferred to the workpiece was predicted to vary between $17 \%$ and $23 \%$ for increasing current from 2 to $19 \mathrm{~A}$ (for a fixed pulse-on time $8 \mu \mathrm{s}$ ); and between $7 \%$ and 53 $\%$ for increasing pulse-on time from 2 to $64 \mu$ s (for fixed current of $10 \mathrm{~A}$ ). A maximum value of $F_{v}$ was attained for the highest pulse-on time of $64 \mu \mathrm{s}$.

Estimates for crater depth from the modelling compared well with experimentally determined values for coating thickness, except for the case of high pulse-on times where there was more variability, but generally, crater sizes (layer thicknesses) increased as the amount of energy transferred to the workpiece increased. Further, the predictions for heat transfer and cooling of the melt pool compared well with experimental observations for the developed cermet microstructures, as a function of processing conditions. In particular, intermediate 
processing conditions of $10 \mathrm{~A}$ and $8 \mu$ s were associated with the development of complex, banded, fine-grained microstructures, reflecting differences in localised cooling rates and the competing pathways for heat conduction into the substrate and convection within the dielectric fluid. Increasing the pulse-on time was characterised by a propensity towards more columnar growth, reflecting the higher energies imparted into the coatings and slower cooling rates.

\section{Acknowledgements}

Samer J. Algodi thanks the Ministry of Higher Education \& Scientific Research in Iraq for funding support. A.T. Clare would like to acknowledge funding from Engineering and Physical Sciences Research Council [grant number EP/L017547/1]. In addition, the authors acknowledge the kind support of Mr Iwasaki of Mitsubishi Electric Nagoya.

\section{References}

Algodi, S.J., Murray, J.W., Fay, M.W., Clare, A.T., Brown, P.D., 2016. Electrical discharge coating of nanostructured TiC-Fe cermets on 304 stainless steel. Surface and Coatings Technology 307, 639-649.

Das, S., Klotz, M., Klocke, F., 2003. EDM simulation: finite element-based calculation of deformation, microstructure and residual stresses. Journal of Materials Processing Technology 142, 434-451.

Descoeudres, A., Hollenstein, C., Wälder, G., Perez, R., 2005. Time-resolved imaging and spatially-resolved spectroscopy of electrical discharge machining plasma. Journal of Physics D: Applied Physics 38, 4066.

DiBitonto, D.D., Eubank, P.T., Patel, M.R., Barrufet, M.A., 1989. Theoretical models of the electrical discharge machining process. I. A simple cathode erosion model. Journal of Applied Physics 66, 4095-4103.

Erden, A., 1983. Effect of materials on the mechanism of electric discharge machining (EDM). Journal of Engineering Materials and Technology 105, 132-138.

Eubank, P.T., Patel, M.R., Barrufet, M.A., Bozkurt, B., 1993. Theoretical models of the electrical discharge machining process. III. The variable mass, cylindrical plasma model. Journal of applied physics 73, 7900-7909.

Ikai, T., Hashigushi, K., 1995. Heat input for crater formation in EDM, Proceedings of the International Symposium for Electro-Machining-ISEM XI, EPFL, pp. 163-170.

Izquierdo, B., Sanchez, J., Plaza, S., Pombo, I., Ortega, N., 2009. A numerical model of the EDM process considering the effect of multiple discharges. International Journal of Machine Tools and Manufacture 49, 220-229.

Joshi, S., Pande, S., 2010. Thermo-physical modeling of die-sinking EDM process.

Journal of manufacturing processes 12, 45-56.

Kansal, H., Singh, S., Kumar, P., 2008. Numerical simulation of powder mixed electric discharge machining (PMEDM) using finite element method. Mathematical and Computer Modelling 47, 1217-1237.

Kojima, A., Natsu, W., Kunieda, M., 2008. Spectroscopic measurement of arc plasma diameter in EDM. CIRP Annals-Manufacturing Technology 57, 203-207.

Kunieda, M., Lauwers, B., Rajurkar, K., Schumacher, B., 2005. Advancing EDM through fundamental insight into the process. CIRP Annals-Manufacturing Technology 54, 64-87. Lin, Y.-C., Hwang, L.-R., Cheng, C.-H., Su, P.-L., 2008. Effects of electrical discharge energy on machining performance and bending strength of cemented tungsten carbides. Journal of Materials Processing Technology 206, 491-499. 
Maradia, U., Hollenstein, C., Wegener, K., 2015. Temporal characteristics of the pulsed electric discharges in small gaps filled with hydrocarbon oil. Journal of Physics D: Applied Physics 48, 055202.

Murray, J., Algodi, S., Fay, M., Brown, P., Clare, A., 2016. Formation mechanism of electrical discharge TiC-Fe composite coatings. Journal of Materials Processing Technology.

Natsu, W., Shimoyamada, M., Kunieda, M., 2006. Study on expansion process of EDM arc plasma. JSME International Journal Series C Mechanical Systems, Machine Elements and Manufacturing 49, 600-605.

Okada, A., Uno, Y., Okajima, I., 2000. Energy Distrihution in Electrical Discharge Machining with Graphite Electrode. energy 1, 1Xe.

Sahoo, C.K., Soni, L., Masanta, M., 2016. Evaluation of microstructure and mechanical properties of TiC/TiC-steel composite coating produced by gas tungsten arc (GTA) coating process. Surface and Coatings Technology 307, 17-27.

Schulze, H.-P., Herms, R., Juhr, H., Schaetzing, W., Wollenberg, G., 2004. Comparison of measured and simulated crater morphology for EDM. Journal of Materials Processing Technology 149, 316-322.

Shabgard, M., Akhbari, S., 2016. An inverse heat conduction method to determine the energy transferred to the workpiece in EDM process. The International Journal of Advanced Manufacturing Technology 83, 1037-1045.

Shahri, H.R.F., Mahdavinejad, R., Ashjaee, M., Abdullah, A., 2016. A Comparative Investigation on Temperature Distribution in Electric Discharge Machining Process through Analytical, Numerical and Experimental Methods. International Journal of Machine Tools and Manufacture.

Shen, Y., Liu, Y., Zhang, Y., Tan, B., Ji, R., Cai, B., Zheng, C., 2014. Determining the energy distribution during electric discharge machining of Ti-6Al-4V. The International Journal of Advanced Manufacturing Technology 70, 11-17.

Singh, H., 2012. Experimental study of distribution of energy during EDM process for utilization in thermal models. International Journal of Heat and Mass Transfer 55, 50535064.

Singh, H., Shukla, D., 2012. Optimizing electric discharge machining parameters for tungsten-carbide utilizing thermo-mathematical modelling. International Journal of Thermal Sciences 59, 161-175.

Singh, S., Bhardwaj, A., 2011. Review to EDM by using water and powder-mixed dielectric fluid. Journal of Minerals and Materials Characterization and Engineering 10, 199.

Singh, S., Maheshwari, S., Pandey, P., 2004. Some investigations into the electric discharge machining of hardened tool steel using different electrode materials. Journal of materials processing technology 149, 272-277.

Somashekhar, K., Panda, S., Mathew, J., Ramachandran, N., 2015. Numerical simulation of micro-EDM model with multi-spark. The International Journal of Advanced

Manufacturing Technology 76, 83-90.

Tan, P., Yeo, S., 2008. Modelling of overlapping craters in micro-electrical discharge machining. Journal of Physics D: Applied Physics 41, 205302.

Tao, J., Ni, J., Shih, A.J., 2012. Modeling of the anode crater formation in electrical discharge machining. Journal of Manufacturing Science and Engineering 134, 011002. Theodore, L., 2011. Heat transfer applications for the practicing engineer. John Wiley \& Sons.

Xia, H., KUNIEDA, M., NISHIWAKI, N., 1996. Removal amount difference between anode and cathode in EDM process. International journal of electrical machining 1, 45-52. XIE, B.-c., WANG, Y.-k., WANG, Z.-I., ZHAO, W.-s., 2011. Numerical simulation of titanium alloy machining in electric discharge machining process. Transactions of Nonferrous Metals Society of China 21, s434-s439.

Yeo, S., Kurnia, W., Tan, P., 2007. Electro-thermal modelling of anode and cathode in micro-EDM. Journal of Physics D: Applied Physics 40, 2513. 
Yeo, S., Kurnia, W., Tan, P., 2008. Critical assessment and numerical comparison of electro-thermal models in EDM. Journal of materials processing technology 203, 241251.

Zhang, Y., Liu, Y., Shen, Y., Li, Z., Ji, R., Cai, B., 2014. A novel method of determining energy distribution and plasma diameter of EDM. International Journal of Heat and Mass Transfer 75, 425-432.

Zhang, Y., Liu, Y., Shen, Y., Li, Z., Ji, R., Wang, F., 2013. A new method of investigation the characteristic of the heat flux of EDM plasma. Procedia CIRP 6, 450-455.

Zhitnyak, I., Gloushankova, N., Levashov, E., Shtansky, D., 2016. Structural

transformations in TiC-CaO-Ti3PO (x)-(Ag2Ca) electrodes and biocompatible TiCaPCO (N)-(Ag) coatings during pulsed electrospark deposition. Surface \& Coatings Technology 302, 327-335.

\section{Figure captions}

Figure 1 Gaussian profile heat source and boundary conditions with the workpiece, including interior node and expanded view of top surface boundary node.

Figure 2 Crater radius as a function of current and pulse-on time obtained experimentally (Table 1).

Figure 3 A process flow highlighting the 2D transient heat transfer model.

Figure 4 Waveforms associated with coatings produced using a TiC tool electrode and a 304 stainless steel workpiece, with negative polarity for pulse-on times of: a) $8 \mu \mathrm{s}$, b) $32 \mu \mathrm{s}$ and c) $64 \mu$ s (fixed $10 \mathrm{~A}$ current).

Figure 5 Fraction of energy transferred to the workpiece, compared to literature (Singh, 2012) and (Shabgard and Akhbari, 2016) as function of increasing: a) current and b) pulse-on time.

Figure 6 MATLAB simulations showing heat distribution into the workpiece at the end of the 'pulse-on' stage; along with the temperature distribution across the top surface (dotted white line) and the boundary of molten material with the bulk substrate (dashed white line).

Figure 7 Plan view SE images of craters created from single spark events, at the start of template coating. Average crater sizes increase with increasing pulse energy.

Figure 8 Simulated crater boundaries into the workpiece as a function of increasing: a) current and b) pulse-on time.

Figures 9 SE images of ED processed coatings, viewed in cross-section: (a,c,e) for fixed pulse-on time of $8 \mu \mathrm{s}$ as a function of increasing current; and $(\mathrm{b}, \mathrm{d}, \mathrm{f})$ for fixed current of $10 \mathrm{~A}$ as a function of increasing pulse-on time. (b:1-3; and c:4-6) Representative localised compositions, determined by EDS, are summarised in Table 4.

Figure 10 Comparison of simulated crater depth from single spark event with experimentally determined EDC layer thicknesses, as a function of increasing: a) current and b) pulse-on time.

Figure 11 BSE images of the developed cermet coating microstructures in cross-section geometry, processed under conditions of: a-d) $10 \mathrm{~A}, 8 \mu \mathrm{s}$; and e-h) $10 \mathrm{~A}, 64 \mu \mathrm{s}$.

Figure 12 Average surface simulated cooling rate for a single TiC crater deposit as a function of: a) Current (fixed pulse-on time of $8 \mu \mathrm{s}$ ) and b) Pulse-on time (fixed current of $10 \mathrm{~A}$ ).

Figure 13 Cooling profiles as a function of increasing time (pulse-off), each line representing a node located at the crater centre (a-l) from the oil-flow/surface interface to the melt/solid with $1 \mu \mathrm{m}$ pitch.

Figure 14 Radial temperature profiles along the top surface of the workpiece as functions of: (a) increasing current and (b) pulse-on time. 


\section{Table captions}

Table 1 EDC machining parameters

Table 2 Material properties of the workpiece and tool electrode

Table 3 Average crater sizes $(n=30)$ as a function of processing conditions

Table 4 Elemental distribution 